\title{
A multidimensional scale of mental workload evaluation based on Individual-Workload-Activity (IWA) model: Validation and relationships with job satisfaction
}

\author{
Edith Galy $\mathrm{a} \otimes(0)$ \\ ${ }^{a}$ Université Côte d’Azur, France
}

\begin{abstract}
The aim of this study is to understand the effect of different mental workload on selfreported performance and job satisfaction. A questionnaire was elaborated to evaluate mental workload from theoretical model IWA (individual-workload-activity). This model is composed to three components (individual physiological, affective, cognitive and social characteristics, three dimensions of mental workload, and activity characteristics with task parameters and execution context) and presents relationships between these components. 616 participants responded to on-line questionnaire. The questionnaire, composed to 40 items, was used to evaluate 4 dimensions plus self-reported performance and job satisfaction (available resources, intrinsic workload, external workload, and germane workload) in order to test their inter-relationships and their relationship with self-reported performance and job satisfaction. First, reliability and validity of the questionnaire were tested. Obtained results are in agreement with IWA model and show that germane load is observed only when operators have sufficient available resources and when tasks to perform are complex and context constrains task execution. Second, job satisfaction appears to be determined by germane load mediated by self-reported performance and organisation and social ambience at work. This study shows the relevance of considering several dimensions of mental workload and their differential effects on job satisfaction and the good psychometric qualities of elaborated questionnaire of evaluation. The questionnaire presented in this study was designed to be used in the enterprises. It seems to be a good tool to pre-diagnose job situations before a more precise analysis of work.
\end{abstract}

Keywords $\backsim$ Mental workload; organisational factors; evaluation; multivariate analysis.

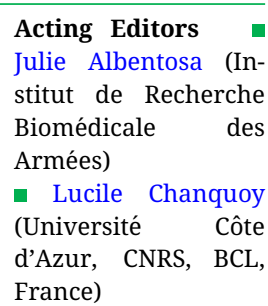

Reviewers

Two anonymous reviewres

edith.galy@univ-cotedazur.fr

10.20982/tqmp.16.3.p240

\section{Introduction}

The aim of this paper is to present an evaluation scale of mental workload based on IWA model (Individual-Workload-Activity; Galy, 2017). This scale is composed to several dimensions and allows to pre-diagnose work situations.

No tool presently exists to evaluate precisely mental workload on the field and to identify parameters of work situation responsible for mental load supported by operators. Many studies are interested by mental workload and, particularly evaluation of mental workload. Different evaluation methods are used currently to evaluate mental workload. These measures can be physiological or subjective. The physiological measures are commonly frontal EEG (So, Wong, Mak, \& Chan, 2017), and heart rate or heart rate variability (Fallahi, Motamedzade, Heidarimoghadam, Soltanian, Farhadian, \& Miyake, 2016). The most used subjective measures are Subjective Workload Assessment Technique (SWAT; Reid \& Nygren, 1988) and NASA-Task Load Index (NASA-TLX; Hart \& Staveland, 1988). Several studies attest that these measures show a good sensitivity to variation of mental load factors (Dey \& Mann, 2010; Fallahi, Motamedzade, Heidarimoghadam, Soltanian, Farhadian, \& Miyake, 2016; Fallahi, Motamedzade, Heidarimoghadam, Soltanian, \& Miyake, 2016; Mohammadi, Ma- 
zloumi, Kazemi, \& Zeraati, 2015; Zongmin, Damin, Xiaoru, Chen, \& Huan, 2014) but two limits for the use of these tools on the field must be highlighted. Firstly, studies are, most of the time, conducted in an experimental context and their results are difficult to transfer to field studies. Secondly, physiological measures are also sensitive to physical workload and require a continuous recording, making them difficult to use on the field. Currently, no measure is totally adapted to an evaluation of mental workload on the field. However, subjective measures are often used in this case and a study by nurses shows that dimensions of NASA-TLX are predicted by performance obstacles. In a study on nurses' workload (Mohammadi et al., 2015) using NASA-TLX to evaluate mental workload, the dimension "mental demand" of NASA-TLX was determined by organisational elements of work situation as presence of "disorganised central stock", "spending much time seeking for supplies in the central stock area", "negative effect of unpredicted problems", and "inadequate help received from nurse assistants". This result consequently indicates that load factors of nurses must be considered in order to identify problematic situation elements and enumerate recommendations improving work situation. A study on driving simulator reported that six dimensions of NASA-TLX do not all measure the same thing, as they were all not sensitive to the same factors (Galy, Paxion, \& Berthelon, 2017). On the field, the more relevant tools to improve work conditions seem to be tools allowing identification and evaluation of load factors rather than tools measuring only globally mental workload. In other words, it seems that diagnostic evaluation of work situation is more efficient by identifying load factors specific to the situation than by assessment of mental workload. This article therefore presents a tool for the evaluation of mental workload based on identification and evaluation of categorised load factors.

Several studies on the field and in laboratory were conducted, looking into relationships between internal state of operator, activity characteristics and context in which activity has been executed to explain mental workload generated by activity (Galy, Cariou, \& Mélan, 2012; Galy \& Gaudin, 2014; Galy \& Mélan, 2015; Galy et al., 2017; Paxion, Galy, \& Berthelon, 2015). These studies allowed to elaborate an integrated explicative model of mental workload (Galy, 2017). The proposed IWA model is composed of three components. The first corresponds to individual characteristics with social, affective, cognitive, and physiological dimensions. The second corresponds to activity and is composed of characteristics of executed tasks and of execution context. The third represents mental workload with three dimensions (intrinsic load, external load and germane load) taken and adapted from the cognitive
Figure 1 Schematic representation of Individual-Worload-Activity (IWA) Model (Galy, 2017).

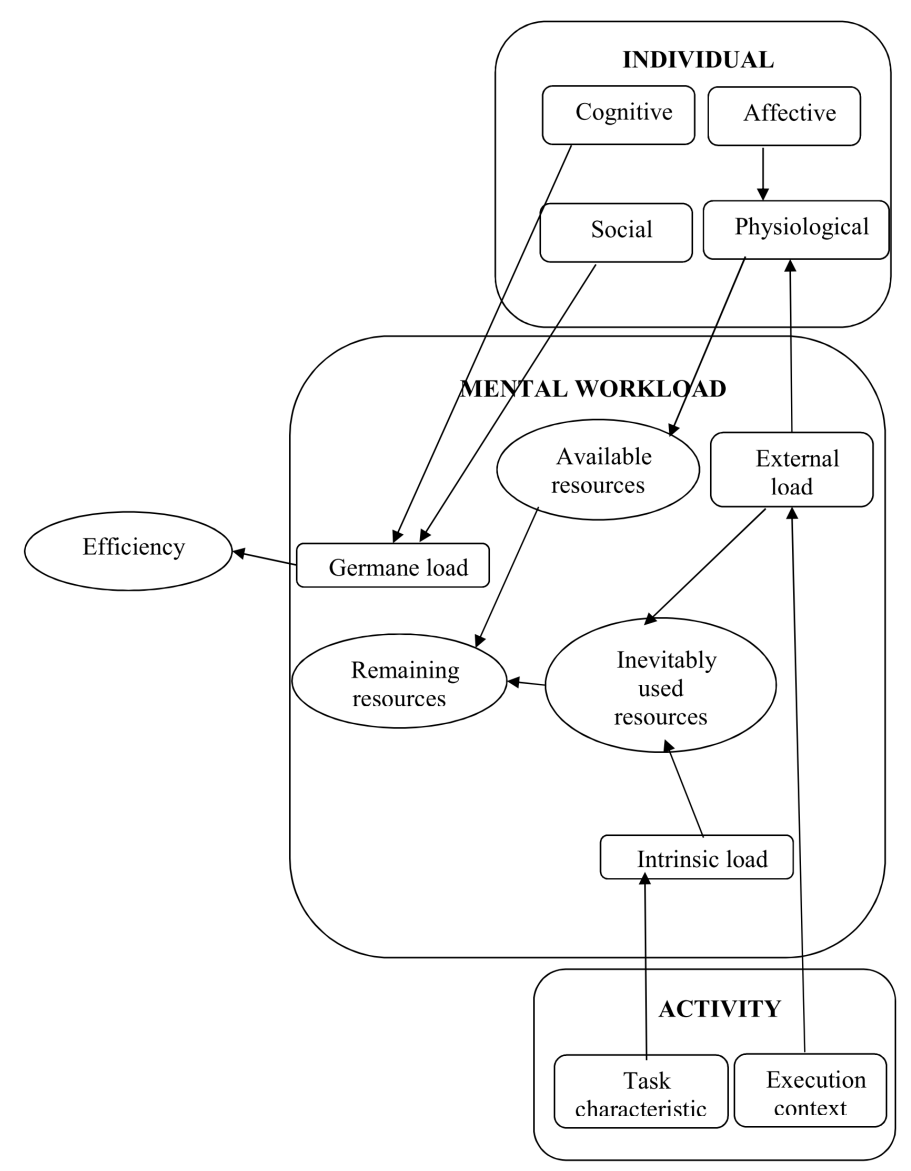

load theory of Sweller (1988). The aim of this model is to represent relationships between these three components (Figure 1).

This model generally shows influence of individual and situational characteristics on mental workload. Mental workload varies as a function of task characteristics (difficulty, complexity, tasks performed in parallel, etc.) and execution context of tasks (social ambience, organisational constraints, sound environment, work in open-space offices,...). Perceived mental workload will be higher when operator has to perform difficult tasks rather than easy (Sweller, 1994) or when sound environment is noisy rather than calm (Kostallari, Parizet, Chevret, Amato, \& Galy, 2018). Concerning individual characteristics, physiological state of an operator, characterised, for example, by his or her level of alertness, will also influence perceived mental workload (Hockey, 2003). This physiological state can be influenced by affective component of operator. Stress thus increases anxiety state but this effect is different as a function of cognitive characteristics of individual as coping or experience in task (Matthews \& Campbell, 2009; Paxion et 
al., 2015).

Experiments specifically conducted in laboratory with memorisation and arithmetic tasks (Galy et al., 2012; Galy \& Mélan, 2015), but also on driving simulator (Galy et al., 2017), showed that individuals' alertness level determines the amount of available resources that can be allocated to different mental workload. Alertness has no direct effect on mental workload but has consequences because load can be more or less important depending on available resources and will allow to perform the task. Some studies (Galy \& Gaudin, 2014; Hoden et al., 2011) showed that only external demands to the task had a significant effect on internal state of operators (alertness or anxiety) and not internal demands. These two types of demands would correspond to intrinsic and external loads postulated by Sweller (1988) in cognitive load theory transposed to ergonomics (Galy, 2017). According to Sweller, intrinsic load corresponds to load generated by task parameters (e.g., task difficulty) and external load corresponds to load generated by context parameters (e.g., computer use to perform task). Thus, external load due to characteristics of execution context would determine alertness contrary to intrinsic load. Concerning the third load category (germane load) corresponding to cost representing establishment of regulatory strategies of activity, no element allows to observe a link with alertness. However, some individual characteristics, as cognitive appraisal or expertise, can influence germane load by determining establishment or not of strategies adapted to the situation (Galy et al., 2012; Galy \& Mélan, 2015; Galy et al., 2017). In addition, when an operator establishes strategies adequate to the situation, he or she will be less easily overloaded and should thus avoid negative effects of mental workload on alertness, performance, health or job satisfaction. Studies particularly show a relationship between mental workload and perceived job performance (Omoloyo \& Omole, 2013) or between mental workload and job satisfaction (Hoden et al., 2011; Idrees, Hafeez, \& Kim, 2017; Van Bogaert, Clarke, Willems, \& Mondelaers, 2012). For this study, self-reported job performance is considered as a multi-dimensional concept determined by several factors comparable to factors of mental workload stated above. Traditional perceived job performance was described on the basis of two components: task performance and contextual performance (Hanif \& Pervez, 2004; Greenslade \& Jimmieson, 2007; Johari \& Yahya, 2012). A third component can also be consider: adaptive performance. It is due to dynamic work environment of some organisations imposing on employees to establish regulatory strategies for adapting their behaviour to frequent changes of work activity (Smith, Ford, Kozlowski, Quinones, \& Ehrenstein, 1997; Pulakos, Arad, Donovan, \& Plamondon, 2000). In our study, we will eval- uate self-reported performance globally, and we will consider different components of job performance through different factors of mental workload. For defining job satisfaction we adopt the Vroom's definition (1964) focusing on the role of the employee in the workplace. This author defines job satisfaction as individuals' perception toward work roles which they are presently occupying. Internal (individual) and external (situational) factors can then influence this perception (Aziri, 2011).

From IWA model, an evaluation scale of mental workload was elaborated. It is composed of four dimensions evaluating intrinsic load, external load, germane load and available resources.

This scale was distributed to operators from all activity sectors to assess the validity of the proposed model explicating mental workload and its impact on self-reported performance and job satisfaction. It is why, in addition to the four enunciated dimensions, job satisfaction and selfreported performance were also evaluated. According to IWA model, we assume that self-reported job performance is determined by the three categories of loads evaluated by the scale.

We can consequently issue four hypotheses. 1) Available resources and intrinsic and external loads should determine germane load. In particular, when resources and intrinsic load decrease and external load increases, germane load should be lower. 2) Self-reported external and intrinsic loads should determine job performance negatively because these load categories represent cost generated by constraints to which operators are subject. Constraints that are more important should correspond to low job performance. 3) Self-reported performance should also be determined positively by germane load. Indeed, if operator can, by taking into account his(her) expertise, resources and his(her) cognitive appraisal of the task, enforce regulation strategies, his(her) self-reported performance should be higher than when these strategies can't be enforced, particularly with high intrinsic and external loads. According to some authors, 4) job satisfaction is as a function of internal and external factors of mental workload (Hoden et al., 2011; Idrees et al., 2017) and perceived self-reported performance (Veloutsou \& Panigyrakis, 2004). We thus assume that available resources, three categories of loads, and self-reported performance should determine job satisfaction (Christen, Iyer, \& Soberman, 2006). Job satisfaction should be higher when available resources, germane and intrinsic loads, and selfreported performance are high, and when external load is low. 
Table 1 a Descriptive statistics of data

\begin{tabular}{|c|c|c|c|c|c|c|c|}
\hline & $\begin{array}{l}\text { Available } \\
\text { resources }\end{array}$ & $\begin{array}{l}\text { Intrinsic } \\
\text { Load }\end{array}$ & $\begin{array}{l}\text { External } \\
\text { load: orga }\end{array}$ & $\begin{array}{l}\text { External } \\
\text { load: } \\
\text { temp }\end{array}$ & $\begin{array}{l}\text { Germane } \\
\text { load }\end{array}$ & $\begin{array}{l}\text { Job satis- } \\
\text { faction }\end{array}$ & $\begin{array}{l}\text { Self- } \\
\text { reported } \\
\text { perfor- } \\
\text { mance }\end{array}$ \\
\hline Mean & 4.67 & 5.965 & 3.97 & 5.09 & 6.38 & 5.65 & 6.00 \\
\hline Standard deviation & 1.34 & 1.37 & 1.36 & 1.34 & .93 & 1.51 & 1.22 \\
\hline Skewness & -.06 & -.78 & .34 & -.29 & -1.02 & -.92 & -1.09 \\
\hline Kurtosis & -.70 & .20 & -.40 & -.36 & 1.62 & 0.52 & 1.64 \\
\hline
\end{tabular}

\section{Material and methods}

\section{Participants}

The survey was distributed to 616 participants (357 females and 259 males) working in all activity sectors in France thanks to professional networks of occupational health specialists. Analyses were conducted on data of 607 (353 females and 254 males) participants because some participants did not answer all the questions. These participants were between ages of 18 and 69 with a mean of 34.32 $(S d=10.13)$.

\section{Material}

This research complied with the American Psychological Association Code of Ethics. Informed consent was obtained from each participant. Conducting collective interviews with workers from all sectors led to the development of 126 questions divided into 5 dimensions (these interviews were conducted within Userlab of platform $\mathrm{H} 2 \mathrm{C} 2$ at AixMarseille University; https://plateformeh2c2.fr/). The first version of the questionnaire was composed originally of 126 items for elements concerning mental workload and two items concerning evaluation of self-reported performance and job satisfaction. 40 items were finally retained to evaluate mental workload. These items obtained the better eigenvalues with principal components analysis. After this analysis, the dimension "external load" was split into two sub-dimensions. The first sub-dimension concerns items corresponding to organisation and social ambiance at work, and the second concerns items corresponding to temporal aspects of work. The 40 questions are distributed in 4 dimensions: intrinsic load (4 items; for example, "Does your job require you to memorize a lot of information?”), external load with two sub-dimension (organisation and social ambiance at work (10 items; for example, "do you find that your objectives are clearly defined?" or "Do you enjoy satisfactory support from your colleagues in difficult situations?”); temporal aspects of work (7 items; for example, "Do you have difficulty following the rhythm imposed by your work?”)), germane load (10 items; for ex- ample, "Compared to your colleagues working under the same conditions, how do you rate your skills?” or "Are you able to verbalize what you do during your work activity?") and available resources (9 items; for example, "Do you feel nervous and agitated?" or "Are you embarrassed in your work by your self-reported emotional states?”). For each item, participants answered on a scale from 1 (totally in disagreement) to 8 (totally in agreement). The French version of the questionnaire is presented in appendices.

\section{Statistics}

Analyses of Cronbach's alpha and correlations were used to test the reliability and validity of questionnaire elaborated to evaluate mental workload.

Generalised additive models (GAM) were used to test linear and non-linear effects of different dimensions of questionnaire and of their interaction on self-reported performance and work satisfaction. GAMs were calculated with gam function of package "Mixed Generalized Additive Model Computation Vehicle with GCV/AIC/REML Smoothness” (mgcv) (Wood, 2006) running on software R 3.1.2 (R Core Team, 2018). These models have the advantage of considering interactions and non-linear relations. Contrary to Generalized Linear Models (GLM), GAMs allow to consider non-linear shapes more flexible than through polynomial transformations (Marx \& Eilers, 1998). Indeed, when changes are more complex than a U-shaped curve relation, GAMs have necessary flexibility to describe correctly nonlinear evolutions of effects (McKeown \& Sneddon, 2014). A second advantage of GAMS is that, during estimation, different possible models are compared to obtain directly the model that best suits the data. To account for relation type (linear or non-linear), predictions were calculated and are presented graphically.

\section{Results}

\section{Descriptive statistics}

General descriptive statistics are presented in Table 1.

These results indicate that participants reported, on average, for all dimensions except external load due to work 
Table 2 - Cronbach's Alpha for each dimension of questionnaire

\begin{tabular}{lc}
\hline Dimensions & Cronbach's $\alpha$ \\
\hline Available resources (9 items) & 0,820 \\
Intrinsic load (4 items) & 0,671 \\
External load: organisation and social ambiance at work (10 items) & 0,842 \\
External load: temporal aspects of work (7 items) & 0,793 \\
Germane load (10 items) & 0,821 \\
\hline
\end{tabular}

organisation and social ambience at work and available resources, levels higher than central value of the scale (4.5). Standard deviations were relatively low. The Skewness indexes indicate data fairly symmetrical for available resources and both sub-dimensions of external load (index between -.5 and .5), data moderately skewed for intrinsic load, germane load, job satisfaction and self-reported performance. Concerning Kurtosis indexes, results show that this index had a value considered very good (index between -1 and +1 ) for available resources, intrinsic load, both sub-dimensions of external load, and job satisfaction, and a value acceptable (index between -2 and -1 , and between 1 and 2) for germane load and self-reported performance. Our data can thus be considered as normal data.

\section{Reliability of questionnaire}

Cronbach's Alpha was calculated for each dimension of questionnaire to test its reliability. We obtained Cronbach's Alphas presented on Table 2.

Analyses of Cronbach's alpha revealed a very good homogeneity of items constitutive of dimensions "available resources", "external load: organisation and social ambiance at work", “external load: temporal aspects of work”, and "germane load” with values of Cronbach's Alpha superior to 0.7. Only Alpha for dimension "intrinsic load" was slightly lower than this value.

\section{Correlation analyses of validity}

Correlation analyses were conducted for each dimension between items constitutive of dimension and corresponding latent variable elaborated with these items for testing the validity of latent variables of the questionnaire. These results are presented in Table 3 and showed that all correlations were significant. Latent variables elaborated for each dimension considered in this questionnaire were valid.

Correlation analyses were also conducted between each dimension of questionnaire, self-reported performance and job satisfaction of operators (Table 4).

These analyses revealed a significant correlation between job satisfaction and self-reported performance, and each dimension of questionnaire except temporal aspects of work of external load. When available resources, ger- mane load and intrinsic load increased, job satisfaction and self-reported performance of operators increased too. On the other hand, when the sub-dimension "organisation and social ambiance at work" of external load increased, job satisfaction and own performance decreased. Moreover, job satisfaction and own performance were positively and significantly correlated. When self-reported performance was high, job satisfaction was too high.

Correlation analyses were finally conducted between available resources and every other dimensions of mental workload questionnaire (Table 5).

Theses correlations showed a significant correlation between available resources and every other dimensions of mental workload questionnaire. When available resources increased, the two sub-dimensions of external load and intrinsic load decreased. On the other hand, when available resources increased, germane load increased too.

\section{Analysis of relationships between mental workload di- mensions, self-reported performance and job satisfac- tion}

GAM analyses were subsequently conducted to test the effect of intrinsic load, two sub-dimensions of external load and available resources on germane load. We obtained a model explaining $20 \%$ of deviance of germane load $\left(r_{a d j}^{2}=\right.$ .184) and we observed a significant linear effect of two sub-dimensions of external load (organisation and social ambiance in work $F(4,602)=26.40, p<.001$, temporal aspects of work $F(4,602)=8.32, p<.005$ ), and a significant effect of interaction between available resources and intrinsic load $F(9,596)=4.99, p<.001)$. Thus, germane load was high when temporal aspects of external load were high and when external load due to organisation and social ambiance in work was low. The graphical result of the interaction between available resources and intrinsic load is presented on Figure 2: it accounts for non-linear relations. Indeed, we can observe two zones characterised by very low germane load. The first zone corresponds to lowest available resources and highest intrinsic load, and the second zone corresponds to highest available resources and lowest intrinsic load. On the other hand, a higher germane load is observed when it exists a good correspondence between these two factors, namely when available resources 
Table 3 - Correlations of each item of each dimension with corresponding latent variable (AR = available resources; IL = intrinsic load; EL orga = external load: organisation and social ambiance at work; EL temp = external load: temporal aspects of work; GL = germane load). ${ }^{* *} p<.01$

\begin{tabular}{ll}
\hline \multicolumn{2}{c}{ Available resources - AR } \\
\hline Item & Pearson's $r$ \\
\hline AR1 & $.444^{* *}$ \\
AR2 & $568^{* *}$ \\
AR4 & $630^{* *}$ \\
AR5 & $693^{* *}$ \\
AR6 & $705^{* *}$ \\
AR7 & $753^{* *}$ \\
AR8 & $722^{* *}$ \\
AR9 & $590^{* *}$ \\
AR10 & $660^{* *}$ \\
\hline
\end{tabular}

\begin{tabular}{lc}
\hline & Intrinsic load - IL \\
\hline Item & Pearson’s $r$ \\
\hline IL1 & $.763^{* *}$ \\
IL2 & $.847^{* *}$ \\
IL3 & $.776^{* *}$ \\
IL4 & $.339^{* *}$ \\
\hline
\end{tabular}

\begin{tabular}{ll}
\hline \multicolumn{2}{c}{ Germane load - GL } \\
\hline Item & Pearson's $r$ \\
\hline GL1 & $.687^{* *}$ \\
Gl2 & $.566^{* *}$ \\
GL3 & $.579^{* *}$ \\
GL4 & $.674^{* *}$ \\
GL5 & $.686^{* *}$ \\
GL6 & $.478^{* *}$ \\
GL7 & $.620^{* *}$ \\
GL8 & $.696^{* *}$ \\
GL9 & $.676^{* *}$ \\
GL10 & $.589^{* *}$ \\
\hline
\end{tabular}

Organisation and social ambiance in work - ELorga

\begin{tabular}{ll}
\hline Item & Pearson's $r$ \\
\hline ELorga 1 & $.673^{* *}$ \\
ELorga 2 & $.557^{* *}$ \\
ELorga 3 & .522 \\
ELorga 4 & $.589^{* *}$ \\
ELorga 5 & $.681^{* *}$ \\
ELorga 6 & $.736^{* *}$ \\
ELorga 7 & $.724^{* *}$ \\
ELorga 8 & $.774^{* *}$ \\
ELorga 9 & $.514^{* *}$ \\
ELorga 10 & $.662^{* *}$ \\
\hline
\end{tabular}

\begin{tabular}{ll}
\multicolumn{2}{l}{ Temporal aspects of work - ELtemp } \\
\hline Item & Pearson's $r$ \\
\hline ELtemp 1 & $.582^{* *}$ \\
ELtemp 2 & $.719^{* *}$ \\
ELtemp 3 & $.703^{* *}$ \\
ELtemp 4 & $.684^{* *}$ \\
ELtemp 5 & $.727^{* *}$ \\
ELtemp 6 & $.611^{* *}$ \\
ELtemp 7 & $.652^{* *}$
\end{tabular}

and intrinsic load are both the highest and the lowest.

Generalised additive models (GAM) analyses were also realised to test the effect of available resources, intrinsic load, two sub-dimensions of external load, germane load and their interactions on self-reported performance. We obtained a model explaining $50.1 \%$ of deviance $\left(r_{a d j}^{2}=\right.$ .493) with a significant linear effect of intrinsic load $F(4,602)=8.08, p<.005$, germane load $F(4,602)=$ $349.55, p<.001$, and interaction between available resources and external load due to organisation and social ambiance in work $F(9,596)=3.56, p<.001$. These results showed that self-reported performance was high when intrinsic and germane loads were high. Graphical result of the interaction between available resources and external load due to organisation and social ambiance in work is presented in Figure 3: it accounts for nonlinear relations. We note that the highest self-reported performance was observed when available resources were the highest and external load due to organisation and social ambiance was moderately high, while the lowest selfreported performance was observed when available resources were the lowest and external load due to organi- sation and social ambiance was the highest. We observed also an intermediary zone characterised by a good selfreported performance when available resources and external load were moderately high. The graph also reveals that available resources are necessary to compensate for very high external load due to organisation and social ambiance in work and access to an acceptable level (superior to mean) of self-reported performance.

If only germane load is considered in statistical model, the results indicate that germane load explained $46.9 \%$ of deviance of self-reported performance $r_{a d j}^{2}=.468$; $F(4,602)=262.3, p<.001$. Thus, concerning selfreported performance, germane load seems to be a mediator variable of effects of available resources and intrinsic and external loads on self-reported performance. These results also indicate that germane load must be superior or equal to 6 for observing an self-reported performance equal to sample mean (mself-reported performance $=6$, Figure 4).

The same GAM analyses were conducted to test the effect of available resources, intrinsic load, two subdimensions of external load, germane load, self-reported 
Table 4 घ Correlations between each dimension of questionnaire of mental workload, self-reported performance, and job satisfaction.

\begin{tabular}{lll}
\hline & $\begin{array}{l}\text { Job satisfaction } \\
\text { Pearson's } r\end{array}$ & $\begin{array}{l}\text { Self-reported performance } \\
\text { Pearson's } r\end{array}$ \\
\hline Self-reported performance & $.368^{* *}$ & \\
Available resources & $.321^{* *}$ & $.150^{* *}$ \\
Intrinsic load & $.113^{* *}$ & $.177^{* *}$ \\
External load: organisation & $-.601^{* *}$ & $-.294^{* *}$ \\
External load: temporal & -.096 & .064 \\
Germane load & $.401^{* *}$ & $.684^{* *}$ \\
\hline
\end{tabular}

Note. ${ }^{*}: p<.05 ; * *: p<.01$

Table 5 a Correlations between available resources and every other dimensions of mental workload questionnaire.

\begin{tabular}{lc}
\hline & Pearson's $r$ \\
\hline Intrinsic load & $-.306^{* *}$ \\
External load: organisation & $-.360^{* *}$ \\
External load: temporal & $-.539^{* *}$ \\
Germane load & $.109^{* *}$ \\
\hline
\end{tabular}

Note. ${ }^{* *}: p<.01$.

performance and their interactions on job satisfaction. Results revealed a model explaining $44.6 \%$ of deviance $\left(r_{a d j}^{2}=.437\right)$ with a significant linear effect of organisation and social ambiance in work of external load on job satisfaction $F(4,602)=115.29, p<.001$, and a significant effect of interaction between self-reported performance and available resources $F(9,596)=8.68, p<.001$. Job satisfaction was thus high when external load due to organisation and social ambience in work was low. A graphical representation of the interaction between self-reported performance and available resources presented in Figure 5 shows a non-linear relation. When self-reported performance is very low or low, job satisfaction is low regardless of the level of available resources. However, when self-reported performance is higher, job satisfaction is as a function of available resources. Job satisfaction thus remains low if available resources are low and it increases if available resources are more important.

Finally, these results also show that external load due to organisation and social ambience in work must be inferior or equal to 4 and available resources must be superior or equal to 4 for observing a job satisfaction equal to sample mean $($ mjob satisfaction $=5.65$, Figure 6$)$.

\section{Discussion}

The results of this study showed that the scale for the evaluation of mental workload elaborated through theoretical model IWA is reliable and valid. Indeed, Cronbach's alphas and correlations realised on the different dimensions of the questionnaire were all high. Selected items to represent each dimension of mental workload seem relevant.

Statistical analyses suggested a model (Figure 7). This model shows that germane load is determined positively by available resources and temporal aspects of external load, and negatively by intrinsic mental workload and organisation and social ambience at work. In turn, germane load determined self-reported performance of operators. Job satisfaction was finally determined positively by selfreported performance and available resources and negatively by external load due to organisation and social ambiance at work.

A main result highlights that when available resources are high, self-reported germane load is high. This result is in agreement with IWA model. In these conditions, operators can establish regulatory strategies of their activity only when they have sufficient available resources (Galy et al., 2012; Galy \& Mélan, 2015; Galy, 2017; Galy et al., 2017). The direction of the effect of intrinsic load and temporal aspects of external load can also be explained by the fact that regulatory strategies are necessary only when tasks to perform are characterised by a certain complexity (intrinsic load high) and when context constrains task execution. Germane load can thus be high only when intrinsic load and/or temporal aspects of work (temporal pressure, cadences,...) are important. However, these factors explain only $20 \%$ of variance of germane load and establishment of regulatory strategies seems principally determined by individual characteristics, as expertise or cognitive appraisal 
Figure 2 - Germane Load index as a function of available resources and intrinsic load. Green lines represent standard deviation to mean.

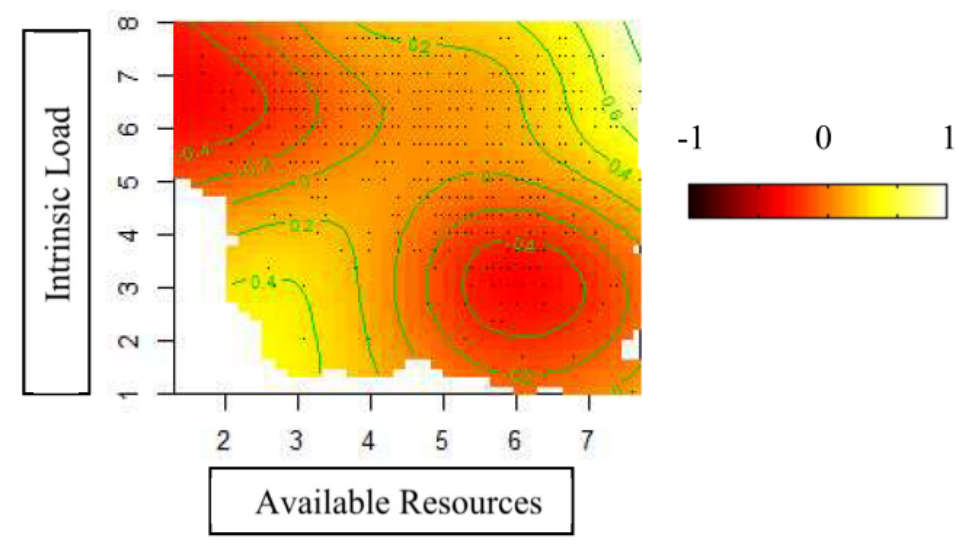

Figure 3 - Germane Load index as a function of available resources and intrinsic load. Green lines represent standard deviation to mean.

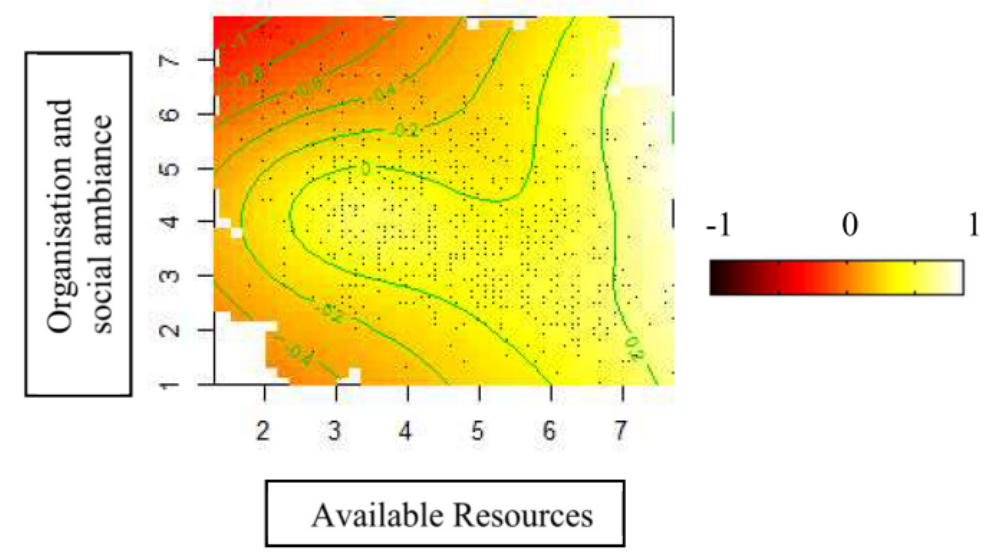

of work situation, factors not taken into account in this study (Galy \& Mélan, 2015; Galy et al., 2017; Paxion et al., 2015; Schnotz \& Kürschner, 2007).

Job satisfaction appears to be determined by germane load mediated by self-reported performance and external load due to organisation and social ambience at work. This result is in agreement with studies showing that social support is an explicative factor of stress and job satisfaction (Sargent \& Terry, 2000). Operators feel efficient in their job only when germane load is present. An overly constrained work context that does not allow the implementation of regulatory strategies of activity thus decreases selfreported performance of operators and consequently their job satisfaction. This possibility of regulation is done primarily by operators' formation and skills, and by aspects of work organisation (constrained procedure, time pressure, unachievable goals, etc.) explaining the relationships ob- served in this study between external load due to organisation and social ambience at work and germane load.

The global results of this study show the relevance of considering several dimensions of mental workload to evaluate it properly. Even though load factors are characterised each by a cognitive cost, loads generated by these different factors do not have the same effect on operators' satisfaction and must thus be considered distinctively.

\section{Conclusion}

Elaborated questionnaire seems to be a tool to diagnose a work situation and to predict self-reported performance and job satisfaction, two factors related to occupational health. In order to reach acceptable level of self-reported performance and job satisfaction and to preserve operators' health, work situation has to be characterised by a score corresponding to germane load superior or equal to 
Figure 4 ॥ Correlation plot between self-reported performance and germane load.

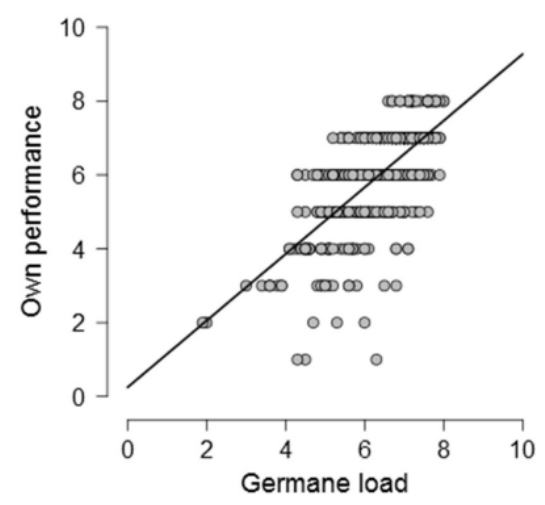

Figure 5 - Work satisfaction as a function of available resources and self-reported performance. Green lines represent standard deviation to mean.

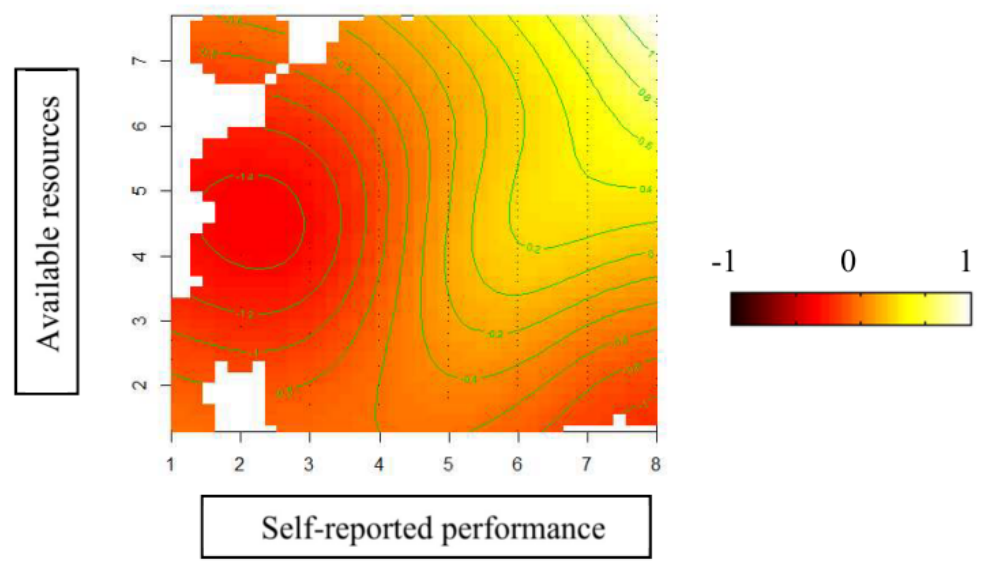

6, to available resources superior or equal to 4 and to external load due to organisation and social ambience in work inferior or equal to 4 . If one of these scores is not reached, work situation can be potentially problematic and represent a risk for occupational health of operators confronted to this situation. To confirm these results, additional studies have to be conducted on the field by taking into consideration occupational health indicators such as the number of sick leave or the statement of health disorders.

\section{Authors' note}

I thank the students of the Aix-Marseille University, particularly Marjorie Mercier, who conducted the preliminary group interviews for the elaboration of the IWA questionnaire. I thank Bruno Dauvier, assistant professor in differential psychology at Aix-Marseille University, who introduced me to the subtleties of $\mathrm{R}$ software in order to perform the statistical analyses presented in this article.

\section{References}

Aziri, B. (2011). Job satisfaction : A literature review. Management Research and Practice, 3(4), 77-86.

Christen, M., Iyer, G., \& Soberman, D. (2006). Job satisfaction, job performance, and effort: A reexamination using agency theory. Journal of Marketing, 70, 137150.

Dey, A., \& Mann, D. D. (2010). Sensitivity and diagnosticity of nasa-tlx and simplified swat to assess the mental workload associated with operating an agricultural sprayer. Ergonomics, 53, 848-857.

Fallahi, M., Motamedzade, M., Heidarimoghadam, R., Soltanian, A. R., Farhadian, M., \& Miyake, S. (2016). Analysis of the mental workload of city traffic control operators while monitoring traffic density: A field study. International Journal of Industrial Ergonomics, 54, 170-177. doi:10.1016/j.ergon.2016.06.005 
Figure 6 — Correlation plots between job satisfaction and available resources (left graph) and job satisfaction and external load due to organisation and social ambience at work (right graph).

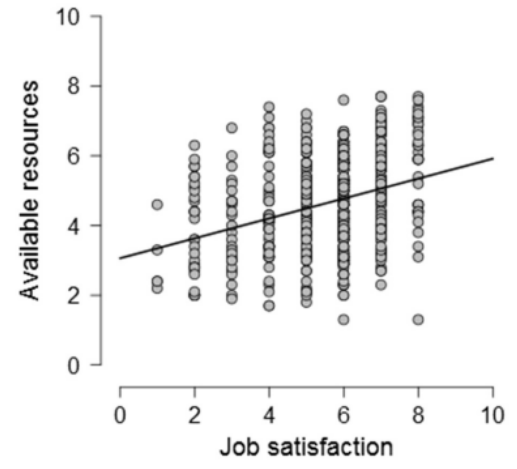

Fallahi, M., Motamedzade, M., Heidarimoghadam, R., Soltanian, A. R., \& Miyake, S. (2016). Effects of mental workload on physiological and subjective responses during traffic density monitoring: A field study. $A p$ plied Ergonomics, 52, 95-103. doi:10.1016/j. apergo. 2015.07.009

Galy, E. (2017). Consideration of several mental workload categories: Perspectives for elaboration of new ergonomic recommendations concerning shiftwork. Theoretical Issues In Ergonomics Science, 19(4), 483497. doi:10.1080/1463922X.2017.1381777

Galy, E., Cariou, M., \& Mélan, C. (2012). What is the relationship between mental workload factors and cognitive load types? International Journal of Psychophysiology, 83, 269-275. doi:10.1016/j.ijpsycho.2011.09.023

Galy, E., \& Gaudin, C. (2014). Vigilance et tension : Effet de l'organisation du travail et de la perception de la situation de travail. Le Travail Humain, 77(4), 301-323. doi:10.3917/th.774.0301

Galy, E., \& Mélan, C. (2015). Effects of cognitive appraisal and mental workload factors on performance to an arithmetic task. Applied Psychophysiology and Biofeedback, 40(4), 313-325. doi:10.1007/s10484-0159302-0

Galy, E., Paxion, J., \& Berthelon, C. (2017). Measuring mental workload with the nasa-tlx needs to examine each dimension rather than relying on the global score: An example with driving. Ergonomics, 61(4), 517-527. doi:10.1080/00140139.2017.1369583

Greenslade, J. H., \& Jimmieson, N. L. (2007). Distinguishing between task and contextual performance for nurses: Development of a job performance scale. Journal of Advanced Nursing, 58(6), 602-611.

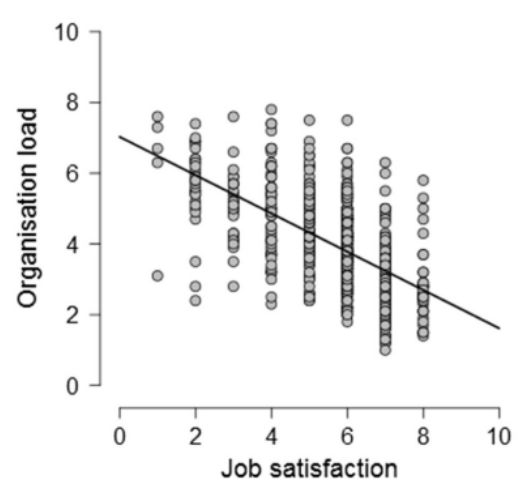

Hanif, R., \& Pervez, S. (2004). Development and validation of teachers job performance scale. Pakistan Journal of Psychological Research, 19, 3-4.

Hart, S. G., \& Staveland, L. E. (1988). Development of nasatlx (task load index): Results of empirical and theoretical research. In Advances in psychology (Vol. 52, pp. 139-183). Elsevier.

Hockey, G. R. J. (2003). Operator functional state in the analysis of complex performance. In H. R. J., A. W. K. Gaillard, \& A. Burov (Eds.), G (pp. 3-7). New York: Operator Functional State: The Assessment and Prediction of Human Performance Degradation in Complex Tasks . Plenum Press.

Hoden, R. J., Scanlon, M. C., Patel, N. R., Kaushal, R., Escoto, H., K., B., L., R., et al. (2011). A human factors framework and study of the effect of nursing workload on patient safety and employee quality of working life. BMJ Quality and Safety, 20, 15-24. doi:10.1136/bmjqs. 2008.028381

Idrees, M. D., Hafeez, M., \& Kim, J.-Y. (2017). Workers’ age and the impact of psychological factors on the perception of safety at construction sites. Sustainability, 9, 115. doi:10.3390/su9050745

Johari, J., \& Yahya, K. K. (2012). An assessment of the reliability and validity of job performance measurement. Jurnal Pengurusan, 36, 17-31.

Kostallari, K., Parizet, E., Chevret, P., Amato, J.-N., \& Galy, E. ( (2018). Irrelevant speech effect in open plan offices: A laboratory study. Crête, Grèce: Conference EURONOISE. Heraklion.

Marx, B., \& Eilers, P. H. C. (1998). Direct generalized additive modeling with penalized likelihood. Computational Statistics \& Data Analysis, 28, 193-209. 
Figure 7 - Schematic representation of obtained model. Full lines represent positive relationships. Dotted lines represent negative relationships.

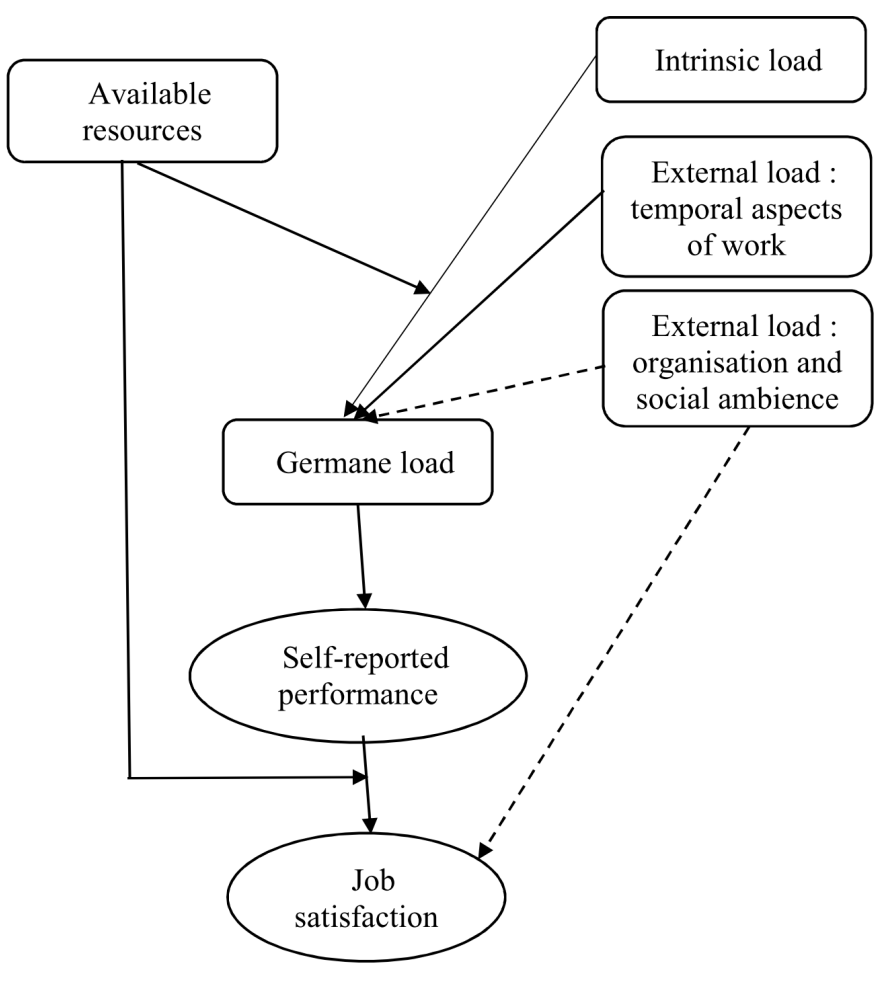

Matthews, G., \& Campbell, S. E. (2009). Sustained performance under overload: Personality and individual differences in stress and coping. Theoretical Issues in Ergonomics Science, 10(5), 417-442.

McKeown, G. J., \& Sneddon, I. (2014). Modeling continuous self-report measures of perceived emotion usinggeneralized additive mixed models. Psychological Methods, 19, 155-174.

Mohammadi, M., Mazloumi, A., Kazemi, Z., \& Zeraati, H. (2015). Evaluation of mental workload among icu ward's nurses. Health Promotion Perspectives, 5(4), 280-287. doi:10.15171/hpp.2015.033

Omoloyo, B. O., \& Omole, O. C. (2013). Influence of mental workload on job performance. International Journal of Humanities and Social Science, 3(15), 238-246.

Paxion, J., Galy, E., \& Berthelon, C. (2015). Overload depending on driving experience and situation complexity: Which strategies faced with a pedestrian crossing? Applied Ergonomics, 51, 343-349. doi:10 . 1016 / j . apergo.2015.06.014

Pulakos, E. D., Arad, S., Donovan, M. A., \& Plamondon, K. E. (2000). Adaptability in the workplace: Development of a taxonomy of adaptive performance. Journal of Applied Psychology, 85, 612-624.

$\mathrm{R}$ Core Team. (2018). R: A language and environment for statistical computing. R Foundation for Statistical Computing. Vienna, Austria. Retrieved from https://www. R-project.org/

Reid, G. B., \& Nygren, T. E. (1988). The subjective workload assessment technique: A scaling procedure for measuring mental workload. In Advances in psychology (Vol. 52, pp. 185-218). Elsevier.

Sargent, L. D., \& Terry, D. J. (2000). The moderating role of social support in karasek's job strain model. Work \& Stress, 14(3), 245-261. doi:10 . 1080/ 02678370010025568

Schnotz, W., \& Kürschner, C. (2007). A reconsideration of cognitive load theory educational psychology review. Educational Psychology Review, 19, 469-508. doi:10 . 1007/s10648-007-9053-4

Smith, E. M., Ford, J. K., Kozlowski, S. W. J., Quinones, M. A., \& Ehrenstein, A. (1997). Building adaptive expertise: Implications for training design strategies. In D. Ford (Ed.), Training for a rapidly changing workplace: Applications of psychological research , , dc: American psy- 
chological association (pp. 89-118). Washington, DC: American Psychological Association.

So, W. K. Y., Wong, S. W. H., Mak, J. N., \& Chan, R. H. M. (2017). An evaluation of mental workload with frontal eeg. PloS ONE, 12(4), 1-17. doi:10.1371/journal.pone. 0174949

Sweller, J. (1988). Cognitive load during problem solving: Effects on learning. Cognitive Science, 12, 257-285. doi:10.1207/s15516709cog1202_4

Sweller, J. (1994). Cognitive load theory, learning difficulty and instructional design. Learning and Instruction, 4, 295-312. doi:10.1016/0959-4752(94

Van Bogaert, P., Clarke, S., Willems, R., \& Mondelaers, M. (2012). Nurse practice environment, workload, burnout, job outcomes, and quality of care in psychiatric hospitals: A structural equation model ap- proach. Journal of Advanced Nursing, 69(7), 15151524. doi:10.1111/jan.12010

Veloutsou, C. A., \& Panigyrakis, G. G. (2004). Consumer brand managers' job stress, job satisfaction, perceived performance and intention to leave. Journal of Marketing Management, 20, 105-131. doi:10.1362/ 026725704773041140

Vroom, V. H. (1964). New York: John Wiley and Sons.

Wood, S. N. (2006). Generalized additive models. An Introduction with R. Londres: Chapman \& Hall.

Zongmin, W., Damin, Z., Xiaoru, W., Chen, L., \& Huan, Z. (2014). A model for discrimination and prediction of mental workload of aircraft cockpit display interface. Chinese Journal of Aeronautics, 27(5), 1070-1077. doi:10.1016/j.cja.2014.09.002

\section{Appendix: Questionnaire}

\section{Available ressources (9 items)}

Est-ce que vos horaires de travail sont fatigants?

Etes-vous sujet(te) à des douleurs physiques (maux de tête, troubles digestifs, douleurs articulaires, etc.)?

Avez-vous des difficultés pour vous concentrer?

Etes-vous sujet(te) à des variations d'humeur?

Etes-vous gêné(e) dans votre travail par vos propres états émotionnels?

Vous sentez-vous nerveux(se) et agité(e)?

Quand vous pensez à votre travail vous arrive-t-il d'être stressé(e)?

Vous arrive-t-il d'être préoccupé(e) par votre avenir professionnel?

Avez-vous le sentiment que vous n'arrivez pas à effectuer tout le travail que vous avez à accomplir?

\section{Intrinsic load (4 items)}

Le travail que vous devez effectuer présente-t-il des incertitudes?

Devez-vous prendre en compte beaucoup d'informations pour réaliser votre travail?

Est-ce que votre travail vous demande de mémoriser beaucoup d'éléments?

Estimez-vous votre travail comme étant stimulant?

\section{External load: organisation and social ambience (10 items)}

Recevez-vous du soutien de la part de vos supérieurs?

Avez-vous la possibilité de gérer votre temps de travail suffisamment à l'avance?

Avez-vous la possibilité de gérer votre planning quotidien?

Trouvez-vous que vos objectifs sont clairement définis?

Bénéficiez-vous d'un soutien satisfaisant de la part de vos collègues dans les situations difficiles?

Le climat qui règne entre les salariés de l'entreprise est-il serein?

Vous sentez-vous suffisamment reconnu pour le travail que vous faites au vu des efforts que vous fournissez?

Recevez-vous le respect qui vous est dû de la part de vos collègues?

Recevez-vous le respect qui vous est dû de la part de vos supérieurs?

Comment estimez-vous la qualité globale de votre matériel?

\section{External load: temporel aspects of work ( 7 items)}

Etes-vous soumis(e) à des augmentations ponctuelles de votre rythme de travail?

Avez-vous des difficultés à atteindre les objectifs, quotas, imposés dans votre travail?

Etes-vous fréquemment interrompu(e) dans votre travail par des tâches imprévues? 
Vous arrive-t-il de réaliser plusieurs tâches en même temps, nécessitant d'en arrêter une pour la reprendre ultérieurement? Etes-vous contraint(e) de donner la priorité à certaines activités au détriment des autres?

Avez-vous des difficultés à suivre le rythme imposé par votre travail?

Etes-vous confronté(e) à des situations de tension dans votre activité?

\section{Germane load (10 items)}

Comment estimez-vous vos compétences dans votre domaine?

Par rapport à vos collègues qui travaillent dans les mêmes conditions, comment estimez-vous vos compétences?

Vous sentez-vous capable d'expliquer de manière simple votre travail à une autre personne?

Possédez-vous un savoir-faire qui vous aide à être plus efficace dans votre travail?

Etes-vous capable d'être autonome dans le travail que vous avez à réaliser?

Tenez-vous absolument à être très bon dans votre travail, sinon vous seriez déçu?

Etes-vous capable de verbaliser ce que vous faites lors de votre activité professionnelle?

Parvenez-vous facilement à jongler entre différentes tâches dans votre travail?

Parvenez-vous facilement à reprendre une activité qui a dû être interrompue?

Estimez-vous que votre propre travail soit utile à l'entreprise?

\section{Job satisfaction (1 item)}

Comment estimez-vous votre satisfaction dans vos activités professionnelles?

\section{Self-reported performance (1 item)}

Comment estimez-vous votre performance dans vos activités professionnelles?

\section{Citation}

Galy, E. (2020). A multidimensional scale of mental workload evaluation based on individual-workload-activity (iwa) model: Validation and relationships with job satisfaction. The Quantitative Methods for Psychology, 16(3), 240-252. doi:10.20982/tqmp.16.3.p240

Copyright ( $\odot$ 2020, Galy. This is an open-access article distributed under the terms of the Creative Commons Attribution License (CC BY). The use, distribution or reproduction in other forums is permitted, provided the original author(s) or licensor are credited and that the original publication in this journal is cited, in accordance with accepted academic practice. No use, distribution or reproduction is permitted which does not comply with these terms.

Received: 24/10/2018 Accepted: 11/06/2019 